\title{
ARTICLE
}

Lymphoma

\section{Transient stabilization, rather than inhibition, of MYC amplifies extrinsic apoptosis and therapeutic responses in refractory B-cell lymphoma}

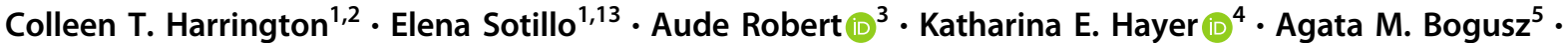 \\ James Psathas ${ }^{1,14}$ - Duonan $\mathrm{Yu}^{1,15} \cdot$ Deanne Taylor $\mathbb{1}^{4,6} \cdot$ Chi V. Dang ${ }^{7} \cdot$ Peter Klein ${ }^{2,8} \cdot$ Michael D. Hogarty $^{9,2,6}$. \\ Birgit Geoerger $^{10,11} \cdot$ Wafik S. El-Deiry ${ }^{12} \cdot$ Joëlle Wiels $\mathbb{D}^{3} \cdot$ Andrei Thomas-Tikhonenko $\mathbb{D}^{1,2,5,9}$
}

Received: 23 November 2016 / Revised: 11 March 2019 / Accepted: 13 March 2019 / Published online: 26 March 2019

(c) The Author(s) 2019. This article is published with open access

\begin{abstract}
Therapeutic targeting of initiating oncogenes is the mainstay of precision medicine. Considerable efforts have been expended toward silencing MYC, which drives many human cancers including Burkitt lymphomas (BL). Yet, the effects of MYC silencing on standard-of-care therapies are poorly understood. Here we found that inhibition of MYC transcription renders B-lymphoblastoid cells refractory to chemotherapeutic agents. This suggested that in the context of chemotherapy, stabilization of Myc protein could be more beneficial than its inactivation. We tested this hypothesis by pharmacologically inhibiting glycogen synthase kinase $3 \beta$ (GSK-3 $\beta$ ), which normally targets Myc for proteasomal degradation. We discovered that chemorefractory BL cell lines responded better to doxorubicin and other anti-cancer drugs when Myc was transiently stabilized. In vivo, GSK3 inhibitors (GSK3i) enhanced doxorubicin-induced apoptosis in BL patient-derived xenografts (BL-PDX), as well as in murine MYC-driven lymphoma allografts. This enhancement was accompanied by and required deregulation of several key genes acting in the extrinsic, death-receptor-mediated apoptotic pathway. Consistent with this mechanism of action, GSK3i also facilitated lymphoma cell killing by a death ligand TRAIL and by a death receptor agonist mapatumumab. Thus, GSK3i synergizes with both standard chemotherapeutics and direct engagers of death receptors and could improve outcomes in patients with refractory lymphomas.
\end{abstract}

\section{Introduction}

Therapeutic targeting of initiating oncogenes is the mainstay of precision medicine. It is thought to be most effective in cancers with a single dominant genetic event, of which Burkitt lymphoma (BL) is a prime example. BL is an aggressive subtype of non-Hodgkin's lymphoma that arises from germinal center B-cells [1]. The cytogenetic hallmark of $\mathrm{BL}$ is the $\mathrm{t}(8 ; 14)$ chromosomal translocation that results

These authors contributed equally: Colleen T. Harrington and Elena Sotillo

Supplementary information The online version of this article (https:// doi.org/10.1038/s41375-019-0454-4) contains supplementary material, which is available to authorized users.

Andrei Thomas-Tikhonenko

andreit@pennmedicine.upenn.edu

Extended author information available on the last page of the article in a fusion between the Myc coding sequence and the immunoglobulin heavy locus $(\operatorname{IgH})$ enhancer. Less commonly, MYC is translocated to the immunoglobulin light chain loci, $\operatorname{IgK}$ or $\operatorname{IgL}$ [2]. Given the prevalence of Myc as an oncogenic driver in BL and other cancers [3], numerous efforts have been made to develop Myc-targeting therapeutics [4]. However, in pre-clinical and clinical settings, such compounds are usually tested as monotherapies, often ignoring the question of their interactions with existing standards of care.

The interplay between Myc-targeting compounds and other anti-cancer modalities is made more complicated by the fact that Myc, while driving enhanced growth and proliferation, can also trigger cell death $[5,6]$. This occurs primarily through p53, a well-established tumor suppressor that activates intrinsic/mitochondrial apoptosis [7]. P53 inactivating mutations and Myc deregulation co-occur in $>30 \%$ of BL tumor samples [8], essentially abrogating this signaling axis and conferring chemoresistance. Not surprisingly, doxorubicin (Dox)-based EPOCH-R (etoposide, 
prednisone, vincristine, cyclophosphamide, and doxorubicin with rituximab) and similar regimens, which are standards of care for Burkitt and other aggressive B-lymphomas, fail to cure a significant number of patients, especially those with relapsed or refractory disease $[\mathrm{r} / \mathrm{r} \mathrm{BL}]$ [9]. Nevertheless, p53-independent, Myc-driven cell death has been reported by several laboratories [reviewed in ref. [5]].

In principle, the pro-apoptotic activity of Myc could be leveraged for improved treatment outcomes even in chemoresistant tumors. However, apoptosis is triggered by much higher Myc levels than proliferation [10]. Thus, there could be proliferation without apoptosis but not apoptosis without proliferation. A potential solution to this problem is to transiently increase Myc levels immediately prior to chemotherapy, reap therapeutic benefits, and then allow Myc to return to baseline.

We and others have reported that strengthening the CD19-PI3K-AKT axis is a reliable method to boost MYC protein stability in B-lymphoid cells [11-13]. This finding is consistent with the propensity of glycogen synthase kinase 3 beta (GSK-3 $\beta$ ), which is inhibited by Akt, to phosphorylate Myc at Thr-58, which marks Myc for recognition by the E3 ubiquitin ligase Fbxw7 and subsequent degradation [reviewed in ref. [14]]. Here we report that adding GSK-3 $\beta$ inhibitors to Dox significantly improves therapeutic apoptosis in B-cell lymphomas with inactive p53 and dissect the underlying molecular mechanisms.

\section{Materials and methods}

\section{Cell culturing}

BL and B-lymphoid cell lines were cultured and maintained in RPMI 1640 medium supplemented with $10 \%$ fetal bovine serum (FBS), 2mM L-glutamine, penicillin/streptomycin $(\mathrm{p} / \mathrm{s})$ at $37^{\circ} \mathrm{C}$ and $5 \% \mathrm{CO}$. P493-6 cells and BL cell lines Ramos, Daudi, Raji, and MutuI were acquired from Dr. Riccardo Dalla-Favera. P493-6 cells were authenticated in 2010 through targeted resequencing of the transgenic MYC allele. P53ER/MYC cells were established and cultured as described previously $[15,16]$. PDX MAP-GR-C95BL-1 cells were cultured in RPMI 1640 medium supplemented with $2 \%$ FBS, $2 \mathrm{mM}$ L-glutamine, p/s, and $2 \%$ glucose at $37^{\circ} \mathrm{C}$ and $5 \% \mathrm{CO} 2$.

\section{Cytotoxicity and caspase activity assays}

For cytotoxicity assays, $8 \times 10^{4}$ cells or $5 \times 10^{5}$ cells (for p493-6 p53shRNA) per well of a 96-well plate were treated in triplicate with DMSO, $3 \mu \mathrm{M}$ CHIR, or $5 \mathrm{ng} / \mathrm{mL}$ tetracycline and indicated concentrations of Dox or
TRAIL. After $48-72 \mathrm{~h}$, cell viability was measured using CellTiter-Glo (Promega, G7570) according to the manufacturer's protocol. Luminescent signal was read using a Synergy 2 plate reader (BioTek Instruments, Winooski, VT, USA). GraphPad Prism software (version 7) was used for log-transformed nonlinear regression curve fitting (4 parameter analysis). For caspase activity assays, cells were treated with DMSO or $3 \mu \mathrm{M}$ CHIR and indicated concentrations of Dox or vincristine. $5 \times 10^{4}$ cells were plated in triplicate in a 96-well plate and caspase activity was measured using Caspase-Glo 3/7 Assay (Promega, G8091). Signals were analyzed in a Synergy 2 plate reader.

\section{Allograft and xenograft studies}

Syngeneic tumors of P53ER/MYC cells were established in flanks of F1 hybrid B6129PF1/J 6-8-week-old female mice (Jackson Laboratories stock no. 100492) as described previously [16-19]. Administration of drugs was started once tumors were palpable. A dose of $8 \mathrm{mg} / \mathrm{kg}$ Dox was delivered via intraperitoneal injection. CHIR99021 was dissolved in $10 \%$ DMSO, $45 \%$ polyethylene glycol 400 (Fisher Scientific, P167-1) and 45\% 0.9\% NaCl (Sigma S8776) and delivered via intraperitoneal injection (100 mg/ $\mathrm{kg}$ ). All animal work was conducted under a protocol approved by the Children's Hospital of Philadelphia Animal Care and Use Committee (protocol IAC 18-000902) and by the Gustave Roussy Animal Care and Use Committee (protocol APAFIS\#9399-2017032714402416v3). Xenografts of PDX-MAP-GR-C95-BL-1 cells were established in flanks of ATHYM-Foxn1nu/nu 5-6-week-old male mice. Once tumors became palpable, mice were treated with CHIR99021 and/or Dox as described above. The model was developed in female NSG mice of 6-8 weeks at engraftment within the project Development of Pediatric PDX Models, approved by the experimental ethic committee 26 (CEEA26-Gustave Roussy) under the number 2015032614359689v7, and in accordance with European legislation, as ancillary study of the clinical MAPPYACTS trial (ClinicalTrials.gov identifier NCT02613962).

\section{Statistics}

Statistical analysis was performed on GraphPad Prism software (version 7) by unpaired Student's $t$-test for two group comparisons or one-way ANOVA correcting for multiple comparisons, with similar variance between groups being compared. Error bars represent s.e.m. $\pm \mathrm{SD}$, and $P<$ 0.05 was considered statistically significant. For these experiments, each group is made up of at least three samples to achieve $80 \%$ power. No randomization nor blinding of investigators was performed. 


\section{Results}

\section{MYC Sensitizes to Doxorubicin in a Myc-repressible B-lymphoid cell model}

To address the role of Myc in responses to chemotherapy, we utilized the B-lymphoid cell model p493-6, which expresses a tetracycline-repressible Myc allele and endogenous Myc [20]. However, these cells are TP53 wild type and do not recapitulate the genetics of BL where p53 has been reported to be mutated at a frequency of $\sim 30 \%$ [8]. To make these cells a more suitable model of $\mathrm{r} / \mathrm{r} \mathrm{BL}$, we infected cells with lentiviruses encoding two different p53directed shRNA hairpins and selected the best knockdown for further use (Fig. S1A, arrow). In response to Dox treatment, p53shRNA-infected cells exhibited impaired induction of p53 and also displayed a higher IC50 for Dox following $72 \mathrm{~h}$ of treatment (Fig. S1B, C), making them representative of $\mathrm{r} / \mathrm{r} \mathrm{BL}$. Of note, in the absence of a chemotherapeutic agent, we observed minimal cleavage of PARP in both "high Myc" and "low Myc" states, indicating the ability of this B-lymphoid cell model to tolerate fluctuations in Myc levels. Furthermore, in the "high Myc" state, therapeutic apoptosis was quite robust, as evidenced by elevated levels of cleaved PARP (Fig. 1a, left two lanes). To our surprise, in the "low Myc" state (Fig. 1a, right two lanes), there was minimal cleavage of PARP in response to Dox.

To measure this effect quantitatively, we treated cells with vehicle or tetracycline and increasing concentrations of Dox for $72 \mathrm{~h}$ and found that "low Myc" cells (+tetracycline) were much more resistant to Dox as measured by a 1-log increase in the IC50 (Fig. 1b, S1D). To determine whether sustained Myc expression is required for Dox sensitivity or whether acute Myc activation would suffice, we started with cells in a "low Myc" state and, at the time of plating/Dox treatment, washed off tetracycline from half the cells, to allow for a quick accumulation of Myc. We found that cells with acute Myc activation ("high Myc") were much more sensitive to Dox as measured by a $>1-\log$ decrease in the IC50 (Fig. 1c, S1E). These counterintuitive data indicate that high $\mathrm{Myc}$, while clearly oncogenic, is essential for Dox-mediated apoptosis. This finding prompted us to investigate how Myc could be pushed beyond the apoptotic threshold in $\mathrm{r} / \mathrm{r}$ BL cells under normal growth conditions or upon exposure to chemotherapy.

\section{GSK-3 $\beta$ inhibition stabilizes Myc in BL cell lines}

Since Myc is regulated post-translationally by GSK-3 $\beta$ phosphorylation on the Thr58 residue, we reasoned that treating B-lymphoid cells with GSK-3 $\beta$ inhibitors such as
A

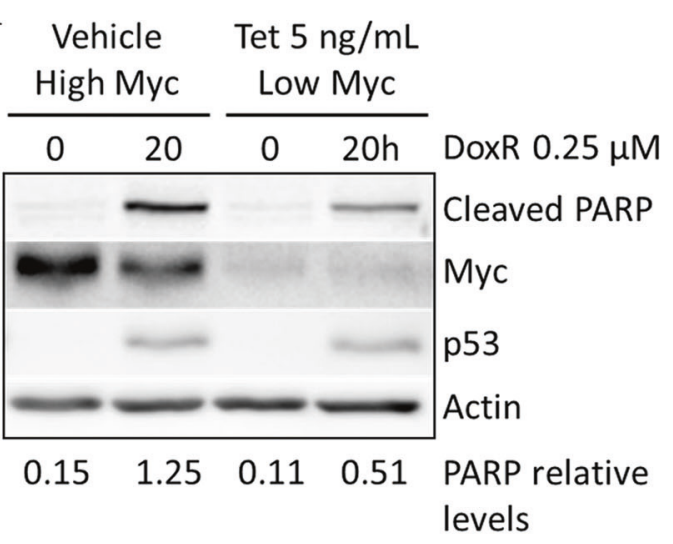

B

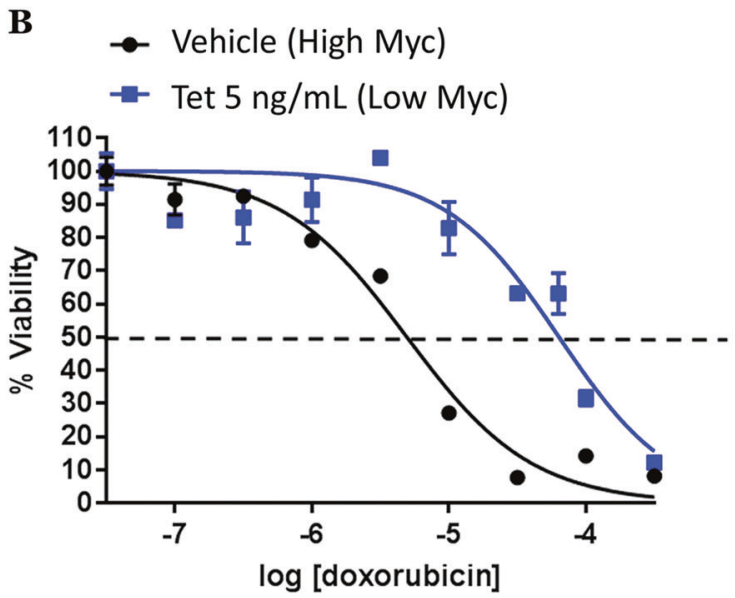

$\mathbf{C}$

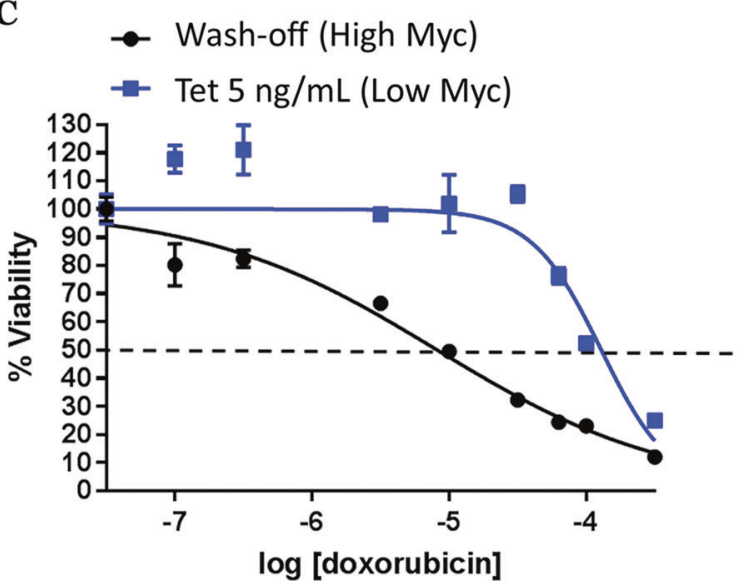

Fig. 1 Myc is critical for doxorubicin sensitivity in a Myc-repressible B-lymphoid model. a P493-6 p53shRNA cells were treated with vehicle (high Myc) or $5 \mathrm{ng} / \mathrm{mL}$ tetracycline (low Myc) for $5 \mathrm{~h}$ and doxorubicin as indicated. Western blotting was performed for cleaved PARP, Myc, p53, and acting loading control. Levels of cleaved PARP (indicated below) were quantified using Image $\mathbf{J}$ software and plotted with GraphPad Prism. b $72 \mathrm{~h}$ Dox dose response curve of p493-6 p53shRNA cells treated with $5 \mathrm{ng} / \mathrm{mL}$ tetracycline or vehicle; survival was assessed using CellTiter-Glo and plotted on GraphPad Prism. c P493-6 p53shRNA cells were treated with $5 \mathrm{ng} / \mathrm{mL}$ tetracycline or vehicle overnight. The next day, tet was removed from half of the cells. All cells were then treated with increasing concentrations of doxorubicin for $48 \mathrm{~h}$ and cell survival was measured as in (b) 
lithium chloride [21] or the more specific small molecule CHIR99021 [22] would elevate Myc to levels sufficient to trigger cell death (Fig. 2a). We first treated a panel of BL cell lines bearing wild type or Thr58-mutant Myc with CHIR99021. $\beta$-catenin, a well-known GSK-3 $\beta$ target [23], was stabilized in all cell lines irrespective of Myc status and thus was used as a readout for GSK3 inhibition in subsequent experiments (Fig. 2b). In contrast, only wild-type Myc was transiently stabilized by CHIR99021 treatment (Fig. 2b). This stabilization was accompanied by the loss of the inhibitory Myc-Thr58 phosphorylation. We also observed Myc stabilization in the Ramos cell line (p53 mutant, Myc wild type) upon GSK-3 $\beta$ inhibition with lithium chloride (Fig. S2A). To determine the mechanism of Myc transient stabilization, we pre-treated Ramos cells with DMSO or CHIR99021, then blocked new mRNA synthesis with actinomycin D. We found no apparent difference in mRNA stability between treatment conditions (Fig. S2B). Ramos cells pre-treated with DMSO or CHIR99021 were then exposed to cycloheximide to inhibit new protein synthesis. In DMSO treated cells, Myc protein was rapidly degraded, with almost all pre-existing protein disappearing after $80 \mathrm{~min}$ (Fig. S2C, DMSO lanes). In contrast, Myc protein in CHIR99021-treated cells was very stable, with little protein loss observed after $80 \mathrm{~min}$ (Fig. S2C, CHIR lanes). Thus, increased protein stability underlies CHIR99021-mediated increases in Myc.

Since both Myc and $\beta$-catenin are able to promote cell cycle progression and in some cases survival, we were concerned that treatment with CHIR99021 alone could promote neoplastic growth. To address this possibility, CHIR99021-treated Ramos cells were assessed for cell cycle distribution, nuclear membrane integrity, and mitochondrial membrane depolarization using flow cytometry for propidium iodide (PI) uptake, Annexin V, and TMRE, respectively. We found no differences in cell cycle distribution or apoptosis (Fig. S2D), suggesting that while short-term treatment with CHIR99021 is unlikely to accelerate cancer progression, it will not be effective as a monotherapy either and would have to be combined with cytotoxic drugs.

\section{GSK-3 $\beta$ inhibition aids chemotherapy in BL by a Myc-dependent mechanism}

To determine whether GSK-3 $\beta$ inhibition potentiates therapeutic apoptosis, we chose a two-hour CHIR99021 pretreatment interval, which coincides with the spike in Myc levels (Fig. 2b). Ramos cells pre-treated with DMSO or CHIR99021 were exposed to Dox or vincristine. We found that CHIR99021 treatment increased activation of apoptosis by both drugs as measured by enhanced PARP cleavage

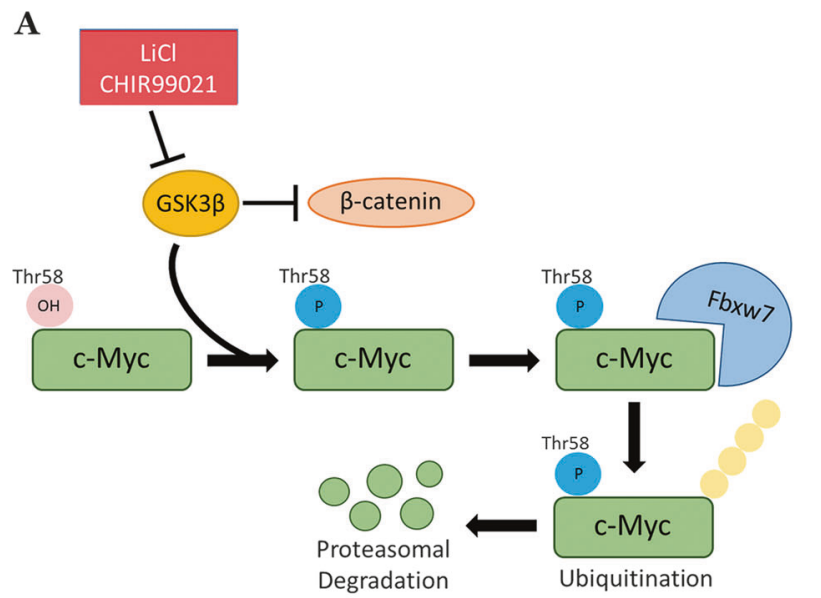

B
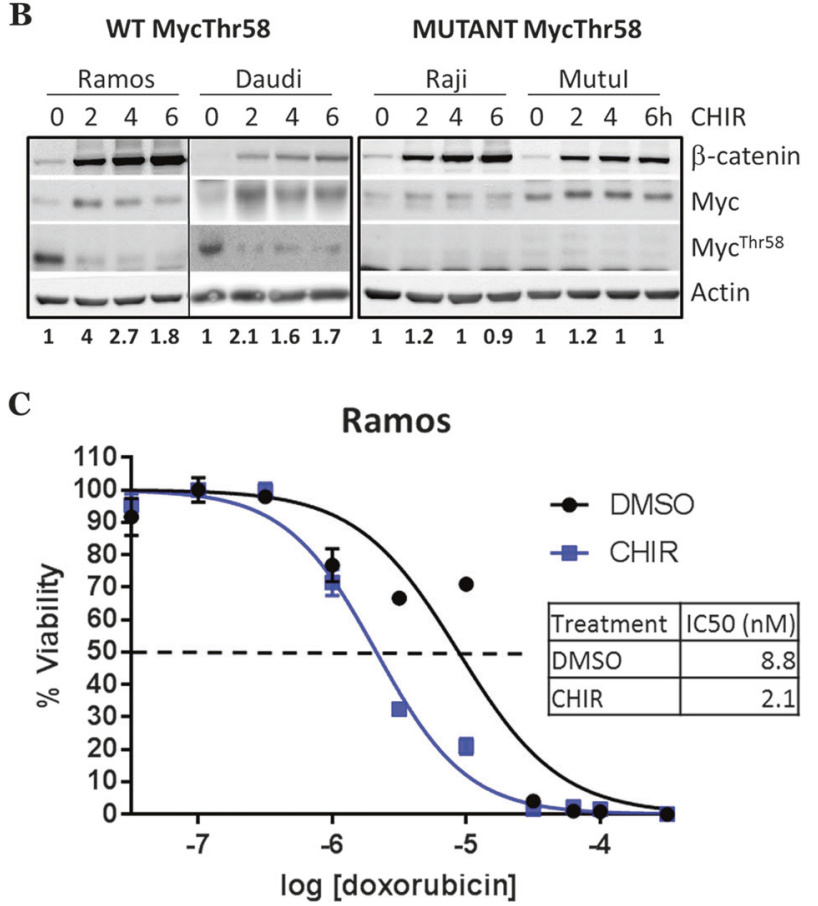

Fig. 2 GSK-3 $\beta$ inhibition stabilizes Myc and increases sensitivity to chemotherapy in Myc wild-type BL cell lines. a Model of Myc protein regulation by GSK-3 $\beta$. b Myc wild type (left) \& Thr58-mutant (right) Burkitt lymphoma cell lines were treated with $3 \mu \mathrm{M}$ CHIR99021 for up to $6 \mathrm{~h}$. Western blotting was performed for $\beta$-catenin, Myc, $\mathrm{Myc}^{\text {Thr58 }}$ phosphorylation, and actin control, with Myc quantification using ImageJ below. c Ramos cells were treated with DMSO or $3 \mu \mathrm{M}$ CHIR99021 and increasing concentrations of doxorubicin for $72 \mathrm{~h}$. Cell survival was assessed as in Fig. 1b

(Fig. S2E, F). As expected, by flow cytometric analysis we observed an increase in cleaved caspase- 3 staining between Dox alone and its combination with CHIR99021 (Fig. S2G).

We also measured apoptosis activation by the CaspaseGlo 3/7 assay, which detects the release of aminoluciferin from the cleaved caspase-3/7-specific substrate. We found 
that CHIR99021 boosted the activation of caspases 3/7 in response to both Dox and vincristine (Fig. S2H, I). As a result, the IC50 for Dox was significantly reduced across multiple experiments (Fig. 2c, S2J). In the BL cell line Daudi (p53 mutant, Myc Thr58 wild type), CHIR99021 also reduced the IC50 for Dox, albeit to a lesser degree (Fig. S2K). Collectively these data demonstrate that GSK$3 \beta$ inhibition enhances the response of $\mathrm{BL}$ cells to chemotherapy.

Given that GSK-3 $\beta$ has targets other than Myc, we asked to what extent this pro-apoptotic effect was due to Myc stabilization. P493-6 p53shRNA cells were treated with vehicle or low dose tetracycline to reduce Myc levels, followed by DMSO or CHIR99021 and Dox. In vehicletreated cells, CHIR99021 lead to increased activation of apoptosis following Dox (Fig. S3A, 'Vehicle' bars/lanes). Tetracycline-treated cells expressed around $\sim 50 \%$ less Myc, and apoptosis following Dox alone was reduced $~ 50 \%$. Despite this, CHIR99021 no longer enhanced the apoptotic response to Dox (Fig. S3A, "Tet" bars/lanes).

In parallel, we pharmacologically inhibited Myc expression in BL cells. Because Myc is regulated at the transcriptional level by BRD4 [24, 25], we employed the BRD4 inhibitor iBet-151 (a.k.a. GSK1210151A) [26] to blunt Myc transcription in the context of CHIR99021 treatment. First, we treated Ramos cells with increasing concentrations of iBet-151 and determined that $500 \mathrm{nM}$ was the lowest dose at which Myc protein levels were adequately suppressed without evidence of cell death (Fig. S3B). We then cultured Ramos cells in $500 \mathrm{nM}$ iBet-151 or control media for $24 \mathrm{~h}$ followed by anti-GSK-3 $\beta$ adjuvant therapy. We found that when Myc expression was reduced, the cooperation between CHIR99021 and Dox was almost fully abrogated, as evidenced by the abolishment of apoptosis markers (Fig. S3C). To measure apoptosis quantitatively, we subjected cells treated with Dox, iBet-151 + Dox, CHIR + Dox, or all three drugs to flow cytometric analysis for apoptosis marker Annexin V. We found that Dox alone did not induce apoptosis very efficiently ( $<15 \%$ Annexin V-positive cells), and adding iBet-151 to Dox made apoptosis even less efficient ( $-7 \%$ net change). Combining CHIR99021 and Dox more than doubled the percentage of Annexin V-positive cells as compared to Dox alone ( 30\%). However, treatment with all three compounds completely blocked apoptosis (Fig. S3D).

To confirm that Myc is required for anti-GSK-3 $\beta$ adjuvant therapy, we tested it on BL cell lines Raji and MutuI that are p53/MycThr58 mutant and do not exhibit a CHIR99021-mediated increase in Myc (Fig. 2b). As anticipated, addition of CHIR99021 did not affect the IC50 for Dox in either of these cell lines (Fig. S3E, F). Collectively, these data suggest that Myc is a key GSK-3 $\beta$ target involved in CHIR99021-facilitated sensitization to chemotherapy.

\section{GSK-3 $\beta$ inhibition aids chemotherapy in vivo in allograft and PDX models}

To test anti-GSK-3 $\beta$ adjuvant therapy in vivo, we first utilized a previously generated non-transgenic p53 conditionallydeficient B-lymphoma model (dubbed "p53ER/MYC") $[16,19]$, wherein bone marrow cells were isolated from p53ER ${ }^{\text {TAM }}$ knockin mice [27] and transduced with retrovirus expressing constitutively active Myc [15]. We confirmed that CHIR99021 treatment transiently stabilized Myc in p53ER/MYC cells (Fig. 3a). In the context of inactive p53 (cells grown without the estrogen receptor (ER) agonist 4-OHT), there was a notable increase in cleaved PARP and cleaved caspase- 3 protein following CHIR + Dox, indicating that Myc stabilization potentiates p53-independent apoptosis in this cell model in vitro (Fig. 3b, quantification in S4A). This pro-apoptotic effect of CHIR99021 was not seen when cells were treated in the context of functional p53 (cells grown in 4-OHT; Fig. S4B). Subsequently, p53ER/MYC allografts grown in mice without 4-OHT treatment were subjected to anti-GSK-3 $\beta$ adjuvant therapy; mice received one intraperitoneal injection of vehicle, CHIR99021, vehicle+Dox, or CHIR99021+Dox. Tumors were harvested $24 \mathrm{~h}$ later and subjected to IHC staining for cleaved caspase-3. We noted a significant increase in positive cells after CHIR99021+Dox treatment compared to Dox alone (Fig. 3c, S4C).

We also developed a patient-derived xenograft (PDX MAP-GR-C95-BL-1) model representing a p53 mutant BL. The model is derived from the pancreatic metastasis of a refractory BL with a TP53 p.Cys135Phe mutation and $\mathrm{LOH}$, as well as a MYC p.Pro78Ser mutation and the subclonal presence of a $t(8 ; 14)$ translocation involving Myc. We confirmed the PDX p53 defect by observing minimal induction of p53 protein following Dox (Fig. S4D). We then inhibited GSK-3 $\beta$ in cultured MAP-GR-C95-BL1 cells with CHIR99021 or $\mathrm{LiCl}$; both resulted in transient Myc stabilization similar to other Myc WT BL cell lines tested (Fig. 4a, S4E). As in Ramos cells, CHIR99021 lowered the IC50 for Dox by roughly half a log, and this decrease in IC50 was significant across multiple experiments (Fig. 4b, S4F). To test this adjuvant therapy in vivo, mice bearing MAP-GR-C95-BL-1 flank xenografts were treated with one intraperitoneal injection of vehicle, Dox, or CHIR99021+Dox; tumors were harvested $24 \mathrm{~h}$ later and processed for IHC measurement of cleaved caspase-3 positive cells. Upon analysis, CHIR99021+Dox treated tumors were significantly more positive than Dox alone- or vehicle-treated tumors (Fig. 4c, S4G). These findings demonstrate that GSK-3 $\beta$ inhibition with CHIR99021 can 

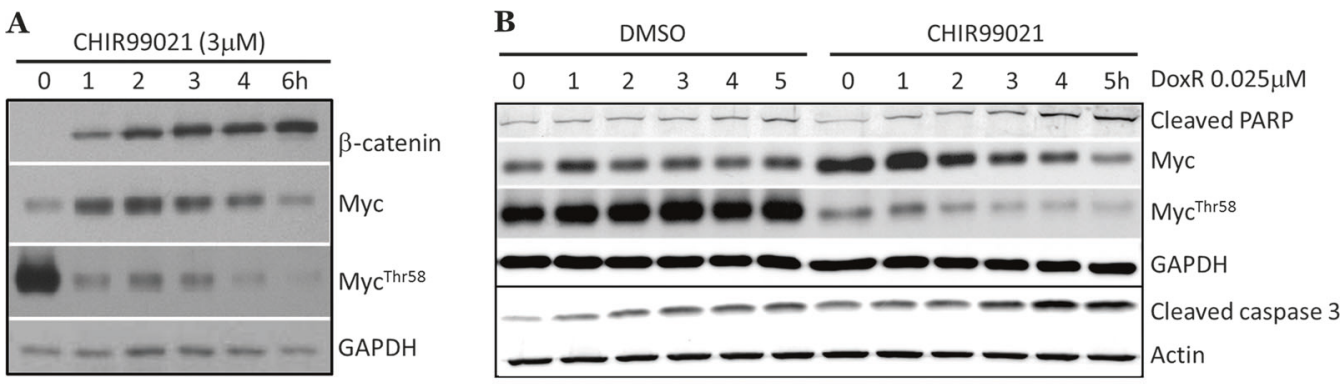

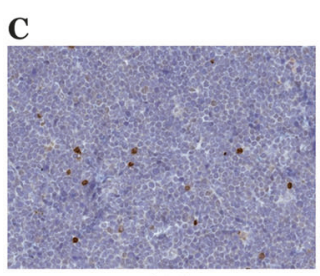

Vehicle

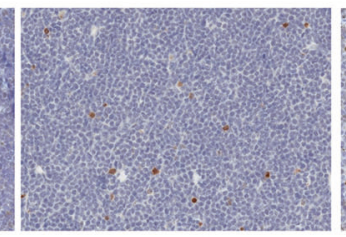

CHIR99021
Fig. 3 GSK-3 $\beta$ inhibition enhances p53-independent apoptosis in syngeneic murine B-cell neoplasms. a p53ER/MYC cells were treated with CHIR99021 as indicated. Western blotting was performed for markers of GSK-3 $\beta$ inhibition. b p53ER/MYC cells were grown without 4-OHT (p53-inactive). Cells were treated with DMSO or $3 \mu \mathrm{M}$ CHIR99021 for $2 \mathrm{~h}$ followed by doxorubicin as indicated. Western blotting was performed for markers of GSK-3 $\beta$ inhibition and

enhance p53-independent apoptosis in vivo in both allograft and PDX models.

\section{Anti-GSK-3 $\beta$ adjuvant therapy engages and relies on extrinsic apoptosis}

To determine the underlying mechanism downstream of Myc, we profiled CHIR99021-mediated transcriptional changes by performing RNA-Seq analysis on Ramos cells treated for 0,3 , or $6 \mathrm{~h}$ with CHIR99021. We first looked for overlap between CHIR99021-induced transcriptome changes and previously reported Myc signatures in two datasets pertaining to p493-6 cells- from microarray profiling ("Psathas Affy" [11]) and array-based nuclear run-on (ANRO) assay ("Dang NRO" [28]). We compared activated genes between the three datasets and found that there were highly statistically significant overlaps between the CHIR99021 and Myc datasets, attesting to the fact that Myc is a key downstream effector of GSK-3 $\beta$ (Fig. S5A).

To examine how apoptosis-related genes were being affected, we further analyzed our RNA-seq dataset at the single gene level. We confirmed that canonical Myc targets, such as ODC1 [29], were being modulated as expected (Fig. S5B). We then visualized up or down-regulated KEGG apoptosis pathway genes (Fig. 5a). Of the significantly altered genes, many were related to extrinsic/ death receptor-driven apoptosis, such as upregulation of RIPK1/TNFR-STK, TRAIL-R4, Death Receptor 4, and downregulation of CFLAR/FLIP, the negative regulator of

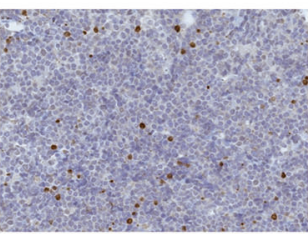

Doxorubicin

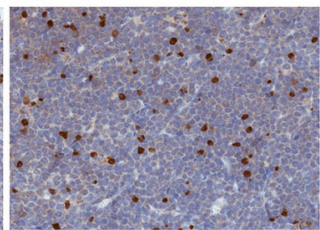

CHIR99021 + Doxorubicin

apoptosis, as well as loading controls. c F1 hybrid B6129PF1/J mice bearing p53ER/MYC subcutaneous grafts were intraperitoneally injected with vehicle, vehicle $+8 \mathrm{mg} / \mathrm{kg}$ doxorubicin, $100 \mathrm{mg} / \mathrm{kg}$ CHIR99021, or $100 \mathrm{mg} / \mathrm{kg}$ CHIR99021 $+8 \mathrm{mg} / \mathrm{kg}$ doxorubicin. Tumors were harvested after $18 \mathrm{~h}$ for immunohistochemistry (IHC). Representative images of cleaved caspase- 3 stains (brown) are shown for each treatment group

extrinsic apoptosis. In contrast, intrinsic/mitochondrial apoptotic genes such as BAX, BAK, and NOXA were not significantly altered.

We validated these findings in cells treated with both CHIR99021 and Dox via qRT-PCR. Once again, we did not observe differential expression in the examined intrinsic apoptosis genes (Fig. 5b). We then re-examined expression of death receptors (Fas, TNFR1, DR4, and DR5), their cognate ligands (FasL, TNF, and TRAIL), and CFLAR/ FLIP. Largely consistent with our RNA-Seq data, we observed upregulation of DR4 and DR5, and downregulation of CFLAR/FLIP (Fig. 5c, yellow arrows); expression of other genes was either absent (FASL; data not shown) or unaffected by CHIR99021. Interestingly, with Dox alone we saw robust upregulation of Fas and TNF, suggesting that chemotherapy alone might engage extrinsic apoptosis to some degree (Fig. 5c).

To experimentally define the role of both apoptotic pathways, we first overexpressed the pathway inhibitor Bcl2 in Ramos cells (Fig. S5C). When we compared CHIR99021-aided apoptosis in empty vector and Bcl-2 expressing cells, we observed enhanced PARP cleavage with CHIR99021 pre-treatment in both cell lines (Fig. 6a). Furthermore, we saw significant activation of caspases-3/7 in both empty vector and $\mathrm{Bcl}-2$ cells treated with CHIR99021+Dox (Fig. S5D), although both basal and GSK-3ßi-aided apoptosis were somewhat reduced by Bcl-2 overexpression, attesting to the involvement of the intrinsic pathway. Given that changes in intrinsic apoptosis had limited effects on therapy efficacy, we tested the 

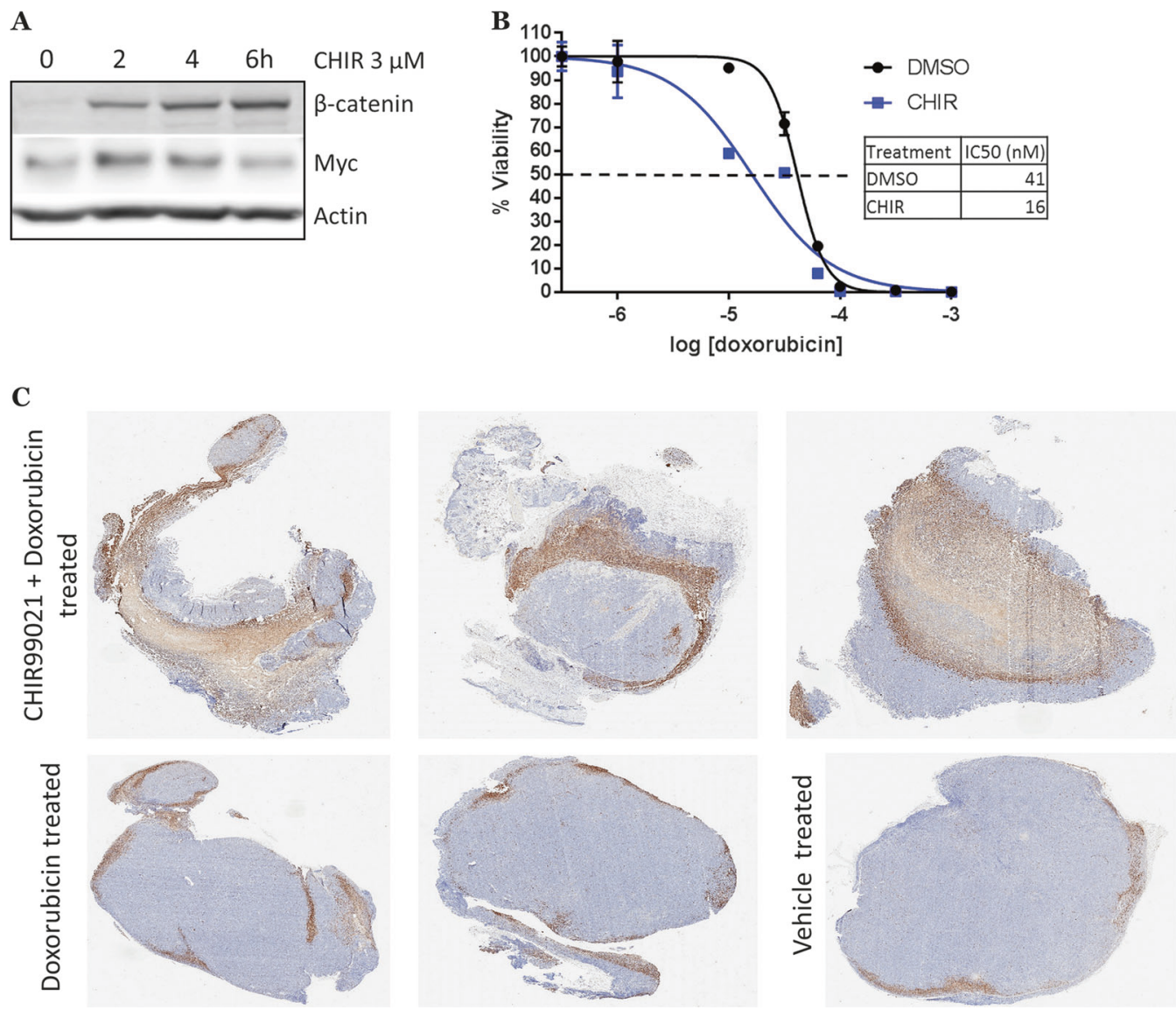

Fig. 4 GSK-3 $\beta$ inhibition increases sensitivity to chemotherapy in Burkitt lymphoma PDX. a PDX MAP-GR-C95-BL-1 cells were treated with CHIR99021 as indicated. Western blotting was performed for $\beta$-catenin and Myc. b PDX MAP-GR-C95-BL-1 cells were treated with DMSO or $3 \mu \mathrm{M}$ CHIR99021 and increasing concentrations of doxorubicin for $72 \mathrm{~h}$. Cell survival was assessed as in Fig. 1b.

c ATHYM-Foxn1nu/nu mice bearing MAP-GR-C95-BL-1 xenografts were intraperitoneally injected with $8 \mathrm{mg} / \mathrm{kg}$ doxorubicin or $100 \mathrm{mg} / \mathrm{kg}$ CHIR99021 $+8 \mathrm{mg} / \mathrm{kg}$ doxorubicin. Tumors were harvested after $24 \mathrm{~h}$ for immunohistochemistry (IHC). Representative images of whole tumors stained for cleaved caspase-3

contribution of the extrinsic apoptotic pathway, which is triggered by binding of death ligands to their cognate receptors and subsequent caspase activation (Fig. S5E). First, we observed that in CHIR99021+Dox treated Ramos cells, there were higher levels of cleaved caspase-8, which is specific to extrinsic apoptosis (Fig. S5F). To test the importance of extrinsic apoptosis, we genetically manipulated members of this pathway. First, we knocked down the extrinsic adaptor protein Fadd mRNA using siRNA and subjected the cells to anti-GSK-3 $\beta$ adjuvant therapy. Despite a modest knockdown ( 30\%, Fig. S5G, left), therapeutic apoptosis was markedly diminished, as evidenced by reduced cleaved caspase- 8 (Fig. S5G, right). To corroborate this observation, we overexpressed caspase- 8 competitor CFLAR (a.k.a c-FLIP) in Ramos cells (Fig. S5H). In empty-vector cells, apoptosis could be readily induced by anti-GSK-3 $\beta$ adjuvant therapy; however, there was an almost complete abrogation of apoptosis in CFLAR/FLIP-overexpressing cells, as evidenced by a

strong reduction in cleaved PARP and cleaved caspase- 8 (Fig. 6b). Similarly, we saw no significant increase in activated caspases in CFLAR/FLIP expressing cells compared to empty vector (Fig. S5I).

To analyze individual contributions of death receptors, we used the CRISPR/Cas9 system to genetically knockout DR4 and DR5. Short guide RNAs (sgRNAs) for DR4, DR5, and a scrambled control sequence were cloned into the LentiCRISPRv2GFP lentiviral vector and stably expressed in Ramos cells. GFP-positive cells were isolated and stained for surface expression of DR4 or DR5; the knockout (KO) lines displayed almost a complete loss of DR4/5 surface expression compared to the scrambled control (Fig. S6A). Knockout was confirmed by western blot for DR4/DR5 protein (Fig. S6B). "Scrambled sgRNA", DR4 and DR5 KO lines were treated with DMSO or CHIR and dilutions of Dox for $72 \mathrm{~h}$. We found that knockout of either DR4 or DR5 did not affect the IC50 of DMSO+Dox compared to the scrambled control; however, in DR4 or DR5 KO lines, 

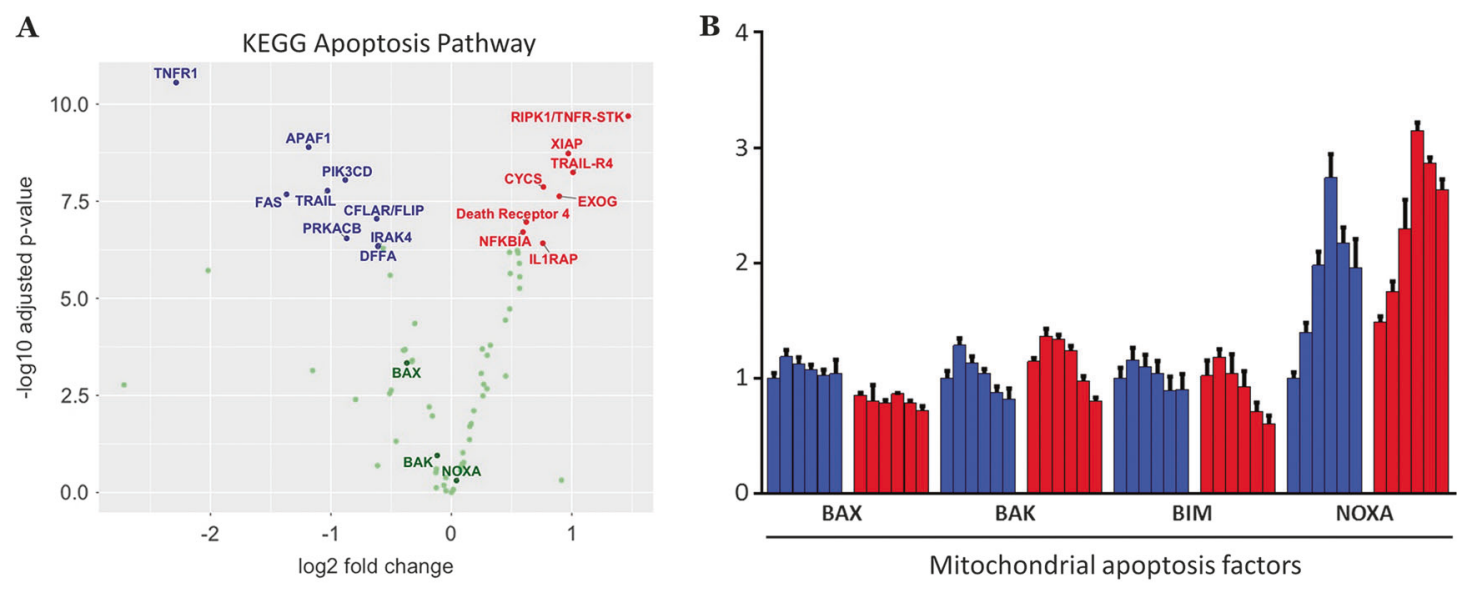

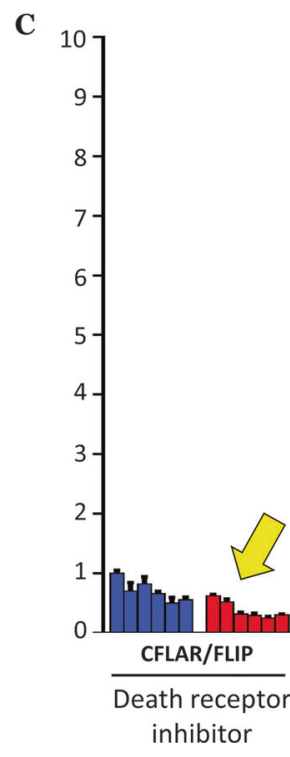

Fig. 5 GSK-3 $\beta$ inhibition alters extrinsic apoptosis genes. a Volcano plot of KEGG apoptosis genes derived from RNA-Seq data on Ramos cells treated for $3 \mathrm{~h}$ with $3 \mu \mathrm{M}$ CHIR99021 in biological triplicates. Key apoptotic genes are labeled, with genes in blue being downregulated, genes in red being upregulated, and genes in green having no significant changes. b qRT-PCR expression analysis for known

CHIR99021 no longer sensitized cells to Dox, as observed across multiple experiments (Fig. 7a, S6C).

Consistent with engagement of extrinsic apoptosis, we found that CHIR99021 lowered the IC50 for the DR4/DR5 ligand TRAIL by $1 \log$ (Fig. 7b). Additionally, we utilized the human DR4 agonist antibody mapatumumab (a.k.a. HGS-ETR1) [30]. Similar to the results with TRAIL, CHIR99021 sensitized Ramos cells to mapatumumab as seen by a half-log reduction in IC50 (Fig. 7c). To determine if DR4 involvement is clinically relevant, we analyzed 10 BL clinical samples for IHC expression of DR4 and compared them to five normal tonsils. We found that while in the tonsillar germinal center the staining was very weakly cytoplasmic, the lymphoma samples displayed robust membrane and cytoplasmic staining (Fig. S6D).
Myc-dependent intrinsic/mitochondrial apoptotic factors was performed on Ramos cells treated for $2 \mathrm{~h}$ with DMSO (blue bars) or $3 \mu \mathrm{M}$ CHIR99021 (red bars) followed by a $6 \mathrm{~h}$ time course of $0.25 \mu \mathrm{M}$ doxorubicin. c qRT-PCR expression analysis for extrinsic apoptosis factors was performed on Ramos cells treated as in (b). Notable changes are indicated with yellow arrows

Collectively these data demonstrate that GSK-3 $\beta$ inhibition potentiates the apoptotic activity of death receptors such as DR4 and reveals the critical dependence of anti-GSK-3 $\beta$ adjuvant therapy on extrinsic apoptosis.

\section{Discussion}

Our studies using murine allografts and human BL cell lines and PDXs demonstrate the benefits of adding GSK3 inhibitors to chemotherapeutic drugs in the R-CHOP/EPOCH-R regimens. They also firmly implicate $\mathrm{Myc}$ as the key downstream target of GSK-3 $\beta$ and a master regulator of chemosensitivity in refractory B-cell lymphomas. Finally, we have learned that Myc-dependent chemosensitivity 
Fig. 6 Disrupting the extrinsic apoptotic pathway abrogates the pro-apoptotic effects of antiGSK-3 $\beta$ adjuvant therapy. a Ramos cells expressing an empty vector construct or the $\mathrm{Bcl}-2$ construct were treated for $2 \mathrm{~h}$ with DMSO or $3 \mu \mathrm{M}$ CHIR99021 followed by a $6.5 \mathrm{~h}$ time course of $0.25 \mu \mathrm{M}$ doxorubicin. Western blotting was performed for Myc, $\mathrm{Myc}^{\mathrm{Th}}{ }^{\mathrm{T} 5}$ phosphorylation, cleaved PARP, and Bcl-2. b Ramos cells expressing an empty vector construct or FLIP construct were treated as in (a). Western blotting was performed for markers of GSK3- $\beta$ inhibition, cell death, and FLIP expression
$\mathbf{A}$

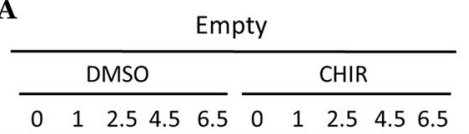

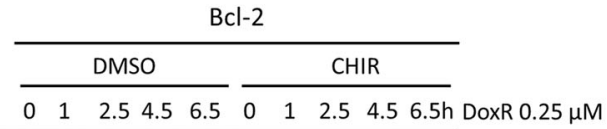
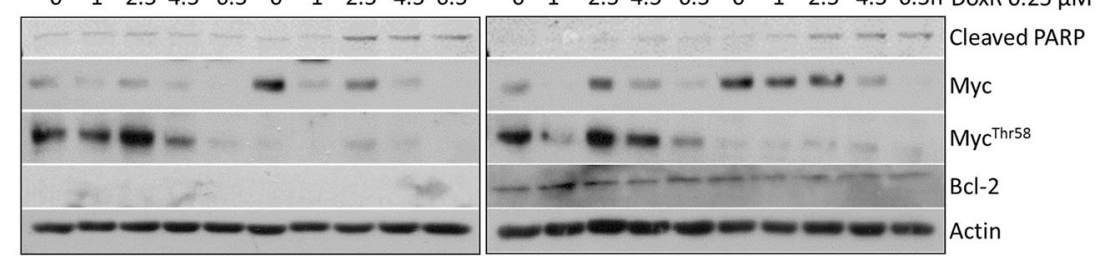

B

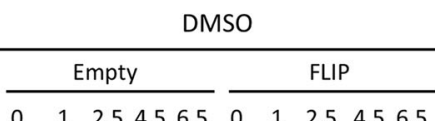

\begin{tabular}{c} 
CHIR \\
\hline Empty \\
\hline
\end{tabular}

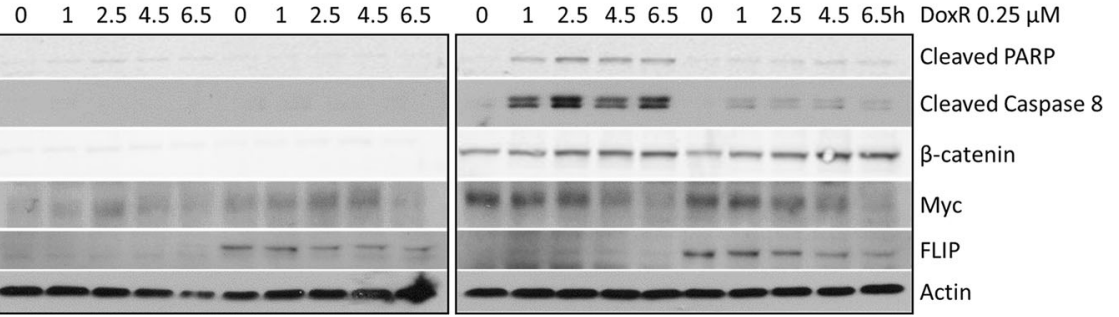

relies on the extrinsic apoptotic pathway, with direct involvement of death receptors such as DR4, whose ligands and agonists function better when GSK-3 $\beta$ is inhibited and Myc is stabilized (Fig. 8). All three key conclusions would be impossible to predict a priori because both GSK-3 $\beta$ and Myc have multitudes of targets with non-overlapping and often conflicting functions.

\section{GSK-3 $\beta$ and therapeutic apoptosis}

The literature on the role of GSK-3 $\beta$ in modulating apoptosis is complex, with some evidence that GSK-3 $\beta$ inhibits the extrinsic apoptotic pathway through an unidentified mechanism, while potentiating the intrinsic pathway [reviewed in ref. [31]]. Thus, its overall contribution to cell survival in the face of genotoxic therapy remains controversial and likely cell type-specific. A 2008 study demonstrated that GSK-3 $\beta$ inhibition in glioblastoma multiforme results in decreased NF- $\mathrm{KB}$ activity [32]. Simultaneously, another group reported the beneficial effects of targeting GSK-3 $\beta$ in a pre-clinical murine model of MLL leukemia, with the underlying mechanism being stabilization of the cyclin-dependent kinase inhibitor p27 [33]. Another firmly established GSK-3 $\beta$ target is PTEN, which is phosphorylated by this kinase on Thr366 and Ser-362 [34]. While Thr366 phosphorylation is thought to lead to PTEN destabilization [35], the contribution of Ser-362 phosphorylation to PTEN function is not known. Given that this tumor suppressor is known to contribute to both intrinsic survival pathways [36] and the extrinsic cell death pathways [37,38], the overall effect of
GSK-3 $\beta$ i on therapeutic apoptosis in B-lymphoid malignancies would have been difficult to predict with certainty. The fact that one of its key targets Myc has manifold effects on tumor cell survival only adds to the complexity of this system.

\section{Myc and extrinsic apoptosis}

The role of Myc in cell death has been incompletely understood, despite the large amount of published studies. While Myc is best known to induce p53-dependent, intrinsic apoptosis, Myc has also been linked to the extrinsic pathway. Notably, it has been shown to participate in apoptosis induced by CD95/CD95L (Fas/FasL) [39], as well as TNF $\alpha$ [40]. Our earlier work reported the relationship between inhibition of GSK-3 $\beta$ and subsequent increase in Myc and enhanced apoptosis in vitro in response to TRAIL [41], at least in part through the propensity of Myc to directly inhibit CFLAR/c-FLIP [42, 43]. In parallel, in some solid cancers Myc elevates expression of the death receptors DR4 and DR5 and the extrinsic ligand FasL [44-46].

While these data, in particular regarding CFLAR/cFLIP, are consistent with the pro-apoptotic function of Myc, there are reports challenging the notion that there is a linear correlation between FLIP levels and TRAIL resistance [see for example ref. [47]]. In addition, our RNA-Seq experiment demonstrated that in Myc-stabilized cells other transcripts went in the opposite, pro-survival direction, with strong downregulation of TNFR1, Fas, and TRAIL. Thus, one could have predicted that stabilization of Myc would limit cell death and by inference confer 


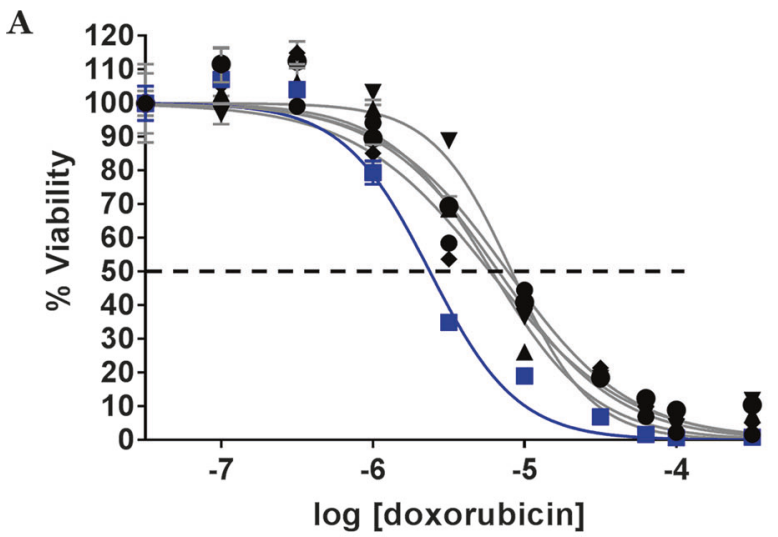

- Scrambled gRNA DMSO $6.7 \mathrm{nM}$

- Scrambled gRNA CHIR $\quad 2.3 \mathrm{nM}$

\ DR4 gRNA DMSO $\quad 6.1 \mathrm{nM}$

$\checkmark$ DR4 gRNA CHIR $\quad 8.2 \mathrm{nM}$

- DR5 gRNA DMSO $\quad 5.9 \mathrm{nM}$

- DR5 gRNa chIR $\quad 7.8 \mathrm{~nm}$
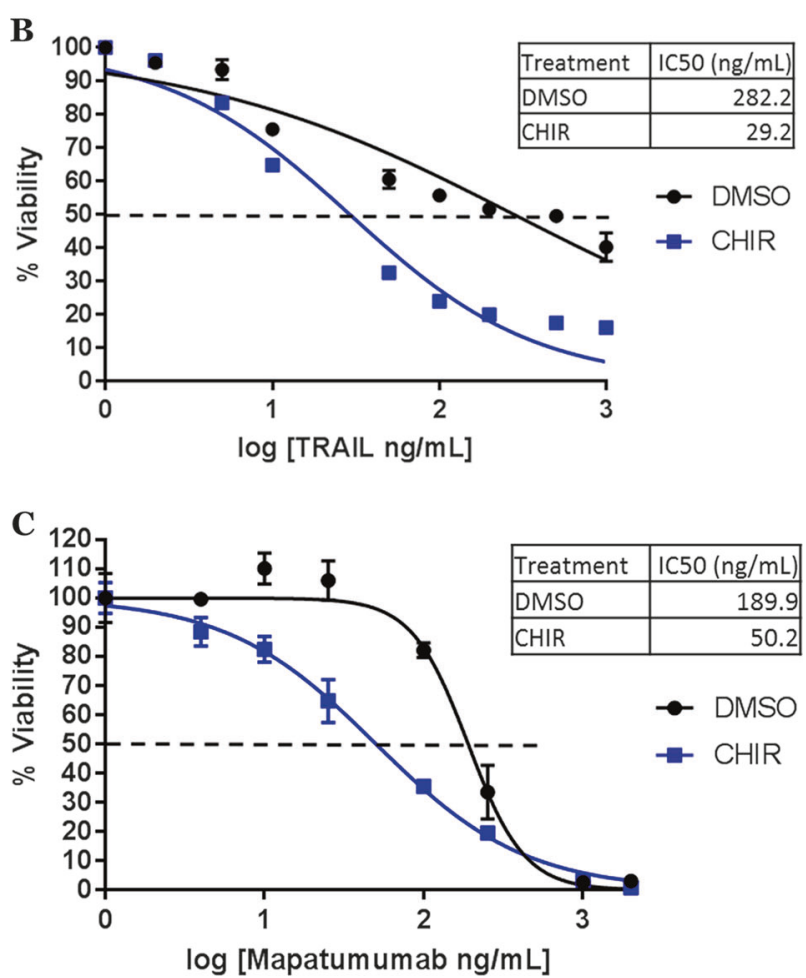

Fig. 7 Anti-GSK-3 $\beta$ adjuvant therapy engages and relies on the extrinsic apoptotic pathway. a Ramos derivative cell lines with scrambled gRNA, DR4 gRNA, and DR5 gRNA were treated and cell survival assessed as in Fig. 2c. b and $\mathbf{c}$ Ramos cells were treated with DMSO or $3 \mu \mathrm{M}$ CHIR99021 and increasing concentrations of TRAIL (b) or mapatumumab (c) for $72 \mathrm{~h}$ and analyzed as in (a)

chemoresistance-or that the effects of Myc on the extrinsic pathway would be irrelevant in the context of genotoxic chemotherapy.

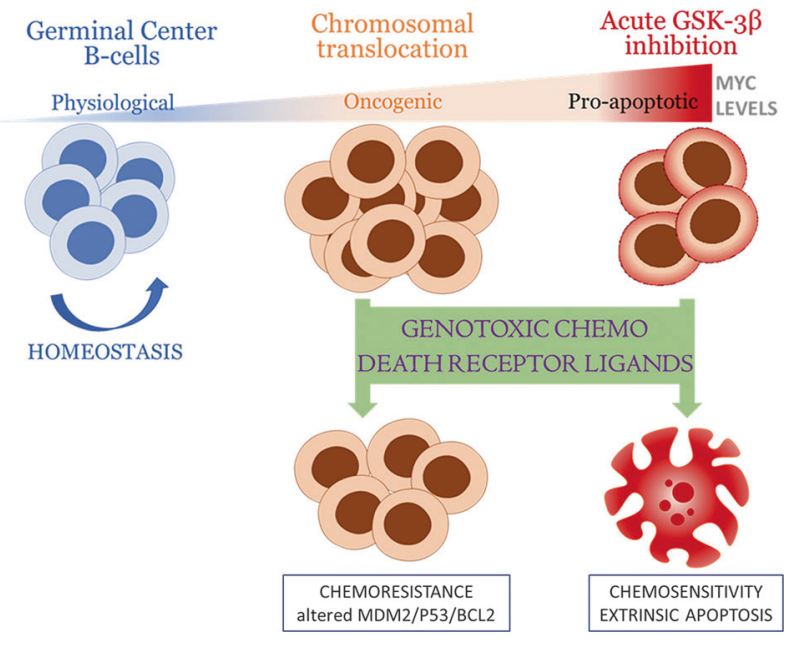

Fig. 8 Model of sensitization of B-cell lymphomas to therapeutic agents by GSK- $3 \beta$ inhibition and stabilization of Myc

\section{Apoptosis-related mechanisms of chemoresistance}

Traditionally, chemoresistance is seen as a failure of the intrinsic pathway. This view is based on the fact that many pro- and anti-apoptotic members of the intrinsic pathway are altered in cancer. For example, IAPs (inhibitors of apoptosis proteins) frequently confer survival to neoplastic cells, especially when overexpressed in tumor cells [48]. Furthermore, the expression and mutation status of Bcl-2 family members is predictive of responses to chemotherapy prognosis: both mutations in the pro-apoptotic gene BAX and overexpression of BCL-2 are common in many cancer types [49]. Therefore, the small molecular inhibitor of Bcl-2 venetoclax has shown considerable promise in pre-clinical and clinical trials, including those involving B-lymphoid malignancies [50].

Despite an established role for intrinsic apoptosis in resistance to chemotherapy, there is also a body of evidence that points to the importance of extrinsic apoptosis for responses to chemotherapy. Published data show that signaling through the death receptor CD95/Fas is critical for chemosensitivity [51]. Conversely, resistance to chemotherapy in leukemia and other cancers can be attributed to downregulation of this death receptor [52]. In addition, mutations in CD95 have been identified in many solid and hematopoietic tumors [reviewed in ref. [53]]. Finally, upregulation of CFLAR/c-FLIP and its increased recruitment to CD95 has been observed in response to various chemotherapeutics in B-ALL and in fact is a resistance mechanism to chemotherapy treatment [54].

Utilizing Ramos BL cells, we observed robust upregulation of Fas mRNA in response to treatment with Dox, while there were minimal changes in intrinsic apoptosis genes. Overexpression of $\mathrm{Bcl}-2$ conferred a very modest 
decrease in Dox induced apoptosis ( $30 \%$ inhibition of caspase $3 / 7$ activity). In contrast, we observed a sharp increase in chemoresistance via overexpression of CFLAR/ c-FLIP or by CRISPR/Cas9 knockout of extrinsic death receptors DR4 or DR5.

\section{Implications for anti-cancer therapeutics}

Data presented throughout the paper suggest that even in the absence of p53, stabilized Myc belongs firmly on the "cell death" side. Notably, when we inhibited Myc transcription with the Brd4 inhibitor iBet-151 at a sub-lethal concentration, there was actually a reduction in GSK3i-aided apoptosis. Thus, in the context of chemotherapy regimens, inactivation of Myc would be counterproductive, as Myc potentiates doxorubicin-induced cell death by engaging extrinsic apoptosis. This observation adds a new wrinkle to the prevailing view that Myc contributes to B-lymphoma cell survival in the face of chemotherapy [see for example ref. [55]].

The results of our studies also suggest several new ways to improve upon standard-of-care therapies for Myc-driven B-cell lymphomas. First, our data suggest that the addition of a GSK-3 $\beta$ inhibitor ( $\mathrm{LiCl}, \mathrm{CHIR} 99021$, or tideglusib currently in Phase II clinical trials for Alzheimer's disease) could enhance the response to chemotherapy even in cells where the intrinsic apoptotic pathway is suppressed. Two such subtypes of B-cell lymphoma associated with poor response to therapy are double- and triple hit lymphomas (Myc and Bcl-2/Bcl-6 translocated) [56], as well as nontranslocated lymphomas double-positive for Myc and Bcl-2 [57]. Second, our findings that anti-GSK-3 $\beta$ adjuvant therapy engages extrinsic apoptosis provides a rationale for revisiting clinical trials of soluble TRAIL or agonistic antibodies targeting DR4 and DR5. Trials with recombinant TRAIL demonstrated safety and tolerability but there was no observed anti-cancer activity in combination with standard-of-care for the cancer types treated. Similarly, with trials using agonistic TRAIL receptor antibodies in combination with standards of care, there was a trend towards anti-cancer activity but no statistically significant results [58]. However, GSK-3 $\beta$ inhibition and ensuing Myc stabilization could make tumor cells more susceptible to the proapoptotic actions of TRAIL or death receptor targeting antibodies such as mapatumumab [59]. Finally, the potential to re-purpose the FDA approved GSK-3 $\beta$ inhibitor lithium chloride makes this adjuvant therapy strategy particularly viable as the process to transition this psychiatric drug to cancer therapy would be relatively unchallenging. Long-term usage of lithium chloride is not correlated with an increase in cancer incidence so it appears to be a safe adjuvant [60].

\section{Data availability}

RNA-Seq data discussed in this publication have been deposited in NCBI Gene Expression Omnibus (GEO) and are accessible through GEO accession number GSE126529.

Acknowledgements The authors thank the members of their laboratories and CHOP Research Institute Normal and Malignant Hematopoiesis Research Affinity Group for stimulating discussions, and Daniel Martinez and the CHOP Pathology Core for assistance in IHC stain analysis. iBet-151 was a kind gift from Dr. Olena Barbash (GlaxoSmithKline) and was first tested in our lab by Daniel Soto de Jesus (University of Pennsylvania). This work was supported by the $\mathrm{V}$ Foundation for Cancer Research, the NIH grants R01CA196299 \& R21 CA183445 (AT-T), R01 HL110806 (PK), T32 GM007229 \& F31 CA217004 (CTH), and the Institut National du Cancer grant PL-BIO 2016-179 (JW). The MAPPYACTS protocol is supported by the Institut National du Cancer grant PHRC-K14-175 and the Fondation ARC grant MAPY201501241. The PDX development is supported and aided by the Société Française de Lutte contre les Cancers et les Leucémies de l'Enfant et l'Adolescent (Fondation Enfants et Santé), the Fondation AREMIG, the Association Thibault BRIET, and the Gustave Roussy animal care facility (Karine Ser-Leroux).

\section{Compliance with ethical standards}

Conflict of interest The authors declare that they have no conflict of interest.

Publisher's note: Springer Nature remains neutral with regard to jurisdictional claims in published maps and institutional affiliations.

Open Access This article is licensed under a Creative Commons Attribution 4.0 International License, which permits use, sharing, adaptation, distribution and reproduction in any medium or format, as long as you give appropriate credit to the original author(s) and the source, provide a link to the Creative Commons license, and indicate if changes were made. The images or other third party material in this article are included in the article's Creative Commons license, unless indicated otherwise in a credit line to the material. If material is not included in the article's Creative Commons license and your intended use is not permitted by statutory regulation or exceeds the permitted use, you will need to obtain permission directly from the copyright holder. To view a copy of this license, visit http://creativecommons. org/licenses/by/4.0/.

\section{References}

1. Dave SS, Fu K, Wright GW, Lam LT, Kluin P, Boerma EJ, et al. Molecular diagnosis of Burkitt's lymphoma. N Engl J Med. 2006;354:2431-42.

2. Dalla-Favera R, Martinotti S, Gallo RC, Erikson J, Croce CM. Translocation and rearrangements of the c-myc oncogene locus in human undifferentiated B-cell lymphomas. Science. 1983;219: 963-7.

3. Dang CV. MYC, metabolism, cell growth, and tumorigenesis. Cold Spring Harb Perspect Med. 2013;3:a014217.

4. McKeown MR, Bradner JE. Therapeutic strategies to inhibit MYC. Cold Spring Harb Perspect Med. 2014;4:a014266.

5. McMahon SB. MYC and the control of apoptosis. Cold Spring Harb Perspect Med. 2014;4:a014407. 
6. Hann SR. MYC cofactors: molecular switches controlling diverse biological outcomes. Cold Spring Harb Perspect Med. 2014;4: a014399.

7. Zindy F, Eischen CM, Randle DH, Kamijo T, Cleveland JL, Sherr $\mathrm{CJ}$, et al. Myc signaling via the ARF tumor suppressor regulates p53-dependent apoptosis and immortalization. Genes Dev. 1998;12:2424-33.

8. Cheung KJ, Horsman DE, Gascoyne RD. The significance of TP53 in lymphoid malignancies: mutation prevalence, regulation, prognostic impact and potential as a therapeutic target. $\mathrm{Br}$ J Haematol. 2009;146:257-69.

9. Dunleavy K, Noy A, Abramson JS, LaCasce AS, Link BK, Parekh S, et al. Risk-adapted therapy in adults with burkitt lymphoma: preliminary report of a multicenter prospective Phase II Study of DA-EPOCH-R. Blood. 2015;126:342-342.

10. Murphy DJ, Junttila MR, Pouyet L, Karnezis A, Shchors K, Bui DA, et al. Distinct thresholds govern Myc's biological output in vivo. Cancer Cell. 2008;14:447-57.

11. Psathas JN, Doonan PJ, Raman P, Freedman BD, Minn AJ, Thomas-Tikhonenko A. The Myc-miR-17-92 axis amplifies Bcell receptor signaling via inhibition of ITIM proteins: a novel lymphomagenic feed-forward loop. Blood. 2013;122:4220-9.

12. Chung EY, Psathas JN, Yu D, Li Y, Weiss MJ, ThomasTikhonenko A. CD19 is a major B cell receptor-independent activator of MYC-driven B-lymphomagenesis. J Clin Invest. 2012;122:2257-66.

13. Sander S, Calado Dinis P, Srinivasan L, Köchert K, Zhang B, Rosolowski M, et al. Synergy between PI3K Signaling and MYC in Burkitt Lymphomagenesis. Cancer Cell. 2012;22:167-79.

14. Farrell AS, Sears RC. MYC degradation. Cold Spring Harb Perspect Med 2014;4:a014365.

15. Yu D, Thomas-Tikhonenko A. A non-transgenic mouse model for B-cell lymphoma: in vivo infection of p53-null bone marrow progenitors by a Myc retrovirus is sufficient for tumorigenesis. Oncogene. 2002;21:1922-7.

16. Amaravadi RK, Yu D, Lum JJ, Bui T, Christophorou MA, Evan GI, et al. Autophagy inhibition enhances therapy-induced apoptosis in a Myc-induced model of lymphoma. J Clin Invest. 2007;117:326-36.

17. Yu D, Cozma D, Park A, Thomas-Tikhonenko A. Functional validation of genes implicated in lymphomagenesis: an in vivo selection assay using a Myc-induced B-cell tumor. Ann NY Acad Sci. 2005;1059:145-59.

18. Yu D, Dews M, Park A, Tobias JW, Thomas-Tikhonenko A. Inactivation of Myc in two-hit B-lymphomas causes dormancy with elevated levels of interleukin-10 receptor and CD20: implications for adjuvant therapies. Cancer Res. 2005;65:5454-61.

19. Yu D, Carroll M, Thomas-Tikhonenko A. p53 status dictates responses of B-lymphomas to monotherapy with proteasome inhibitors. Blood. 2007;109:4936-43.

20. Pajic A, Spitkovsky D, Christoph B, Kempkes B, Schuhmacher M, Staege MS, et al. Cell cycle activation by c-myc in a Burkitt lymphoma model cell line. Int J Cancer. 2000;87:787-93.

21. O'Brien WT, Klein PS. Validating GSK3 as an in vivo target of lithium action. Biochem SocTrans. 2009;37(Pt 5):1133-8.

22. Ring DB, Johnson KW, Henriksen EJ, Nuss JM, Goff D, Kinnick TR, et al. Selective glycogen synthase kinase 3 inhibitors potentiate insulin activation of glucose transport and utilization in vitro and in vivo. Diabetes. 2003;52:588-95.

23. Aberle H, Bauer A, Stappert J, Kispert A, Kemler R. beta-catenin is a target for the ubiquitin-proteasome pathway. EMBO J. 1997; 16:3797-804.

24. Delmore JE, Issa GC, Lemieux ME, Rahl PB, Shi J, Jacobs HM, et al. BET bromodomain inhibition as a therapeutic strategy to target c-Myc. Cell. 2011;146:904-17.
25. Zuber J, Shi J, Wang E, Rappaport AR, Herrmann H, Sison EA, et al. RNAi screen identifies Brd4 as a therapeutic target in acute myeloid leukaemia. Nature. 2011;478:524-8.

26. Dawson MA, Prinjha RK, Dittmann A, Giotopoulos G, Bantscheff $\mathrm{M}$, Chan WI, et al. Inhibition of BET recruitment to chromatin as an effective treatment for MLL-fusion leukaemia. Nature. 2011;478:529-33.

27. Christophorou MA, Martin-Zanca D, Soucek L, Lawlor ER, Brown-Swigart L, Verschuren EW, et al. Temporal dissection of p53 function in vitro and in vivo. Nat Genet. 2005;37:718-26.

28. Fan J, Zeller K, Chen YC, Watkins T, Barnes KC, Becker KG, et al. Time-dependent c-Myc transactomes mapped by Arraybased nuclear run-on reveal transcriptional modules in human $\mathrm{B}$ cells. PLoS ONE. 2010;5:e9691.

29. Bello-Fernandez C, Packham G, Cleveland JL. The ornithine decarboxylase gene is a transcriptional target of c-Myc. Proc Natl Acad Sci USA. 1993;90:7804-8.

30. Pukac L, Kanakaraj P, Humphreys R, Alderson R, Bloom M, Sung C, et al. HGS-ETR1, a fully human TRAIL-receptor 1 monoclonal antibody, induces cell death in multiple tumour types in vitro and in vivo. Brit J Cancer. 2005;92:1430-41.

31. Beurel E, Jope RS. The paradoxical pro- and anti-apoptotic actions of GSK3 in the intrinsic and extrinsic apoptosis signaling pathways. Prog Neurobiol. 2006;79:173-89.

32. Kotliarova S, Pastorino S, Kovell LC, Kotliarov Y, Song H, Zhang W, et al. Glycogen synthase kinase-3 inhibition induces glioma cell death through c-MYC, nuclear factor-kappaB, and glucose regulation. Cancer Res. 2008;68:6643-51.

33. Wang Z, Smith KS, Murphy M, Piloto O, Somervaille TC, Cleary ML. Glycogen synthase kinase 3 in MLL leukaemia maintenance and targeted therapy. Nature. 2008;455:1205-9.

34. Al-Khouri AM, Ma Y, Togo SH, Williams S, Mustelin T. Cooperative phosphorylation of the tumor suppressor phosphatase and tensin homologue (PTEN) by casein kinases and glycogen synthase kinase 3beta. J Biol Chem. 2005;280:35195-202.

35. Maccario H, Perera NM, Davidson L, Downes CP, Leslie NR. PTEN is destabilized by phosphorylation on Thr366. Biochem J. 2007;405:439-44.

36. Stambolic V, Suzuki A, de la Pompa JL, Brothers GM, Mirtsos C, Sasaki T, et al. Negative regulation of PKB/Akt-dependent cell survival by the tumor suppressor PTEN. Cell. 1998;95:29-39.

37. Jayarama S, Li LC, Ganesh L, Mardi D, Kanteti P, Hay N, et al. MADD is a downstream target of PTEN in triggering apoptosis. $\mathrm{J}$ Cell Biochem. 2014;115:261-70.

38. Yuan XJ, Whang YE. PTEN sensitizes prostate cancer cells to death receptor-mediated and drug-induced apoptosis through a FADD-dependent pathway. Oncogene. 2002;21:319-27.

39. Hueber AO, Zornig M, Lyon D, Suda T, Nagata S, Evan GI. Requirement for the CD95 receptor-ligand pathway in c-Mycinduced apoptosis. Science. 1997;278:1305-9.

40. Klefstrom J, Vastrik I, Saksela E, Valle J, Eilers M, Alitalo K. cMyc induces cellular susceptibility to the cytotoxic action of TNFalpha. EMBO J. 1994;13:5442-50.

41. Mayes PA, Dolloff NG, Daniel CJ, Liu JJ, Hart LS, Kuribayashi $\mathrm{K}$, et al. Overcoming hypoxia-induced apoptotic resistance through combinatorial inhibition of GSK-3beta and CDK1. Cancer Res. 2011;71:5265-75.

42. Ricci MS, Kim SH, Ogi K, Plastaras JP, Ling J, Wang W, et al. Reduction of TRAIL-induced Mcl-1 and cIAP2 by c-Myc or sorafenib sensitizes resistant human cancer cells to TRAILinduced death. Cancer Cell. 2007;12:66-80.

43. Ricci S, Jin Z, Dews M, Yu D, Thomas-Tikhonenko A, Dicker DT, et al. Direct repression of FLIP expression by c-myc is a major determinant of TRAIL sensitivity. Mol Cell Biol. 2004;24:8541-55. 
44. Sussman RT, Ricci MS, Hart LS, Sun SY, El-Deiry WS. Chemotherapy-resistant side-population of colon cancer cells has a higher sensitivity to TRAIL than the non-SP, a higher expression of c-Myc and TRAIL-receptor DR4. Cancer Biol Ther. 2007;6:1490-5.

45. Wang Y, Engels IH, Knee DA, Nasoff M, Deveraux QL, Quon KC. Synthetic lethal targeting of MYC by activation of the DR5 death receptor pathway. Cancer Cell. 2004;5:501-12.

46. Kasibhatla S, Beere HM, Brunner T, Echeverri F, Green DRA. 'non-canonical' DNA-binding element mediates the response of the Fas-ligand promoter to c-Myc. Curr Biol. 2000;10:1205-8.

47. Chang DW, Xing Z, Pan Y, Algeciras-Schimnich A, Barnhart BC, Yaish-Ohad S, et al. c-FLIP(L) is a dual function regulator for caspase-8 activation and CD95-mediated apoptosis. EMBO J. 2002;21:3704-14.

48. Fulda S, Vucic D. Targeting IAP proteins for therapeutic intervention in cancer. Nat Rev Drug Discov. 2012;11:109-24.

49. Yip KW, Reed JC. Bcl-2 family proteins and cancer. Oncogene. 2008;27:6398-406.

50. Roberts AW, Davids MS, Pagel JM, Kahl BS, Puvvada SD, Gerecitano JF, et al. Targeting BCL2 with venetoclax in relapsed chronic lymphocytic leukemia. N Engl J Med. 2016;374:311-22.

51. Müller M, Wilder S, Bannasch D, Israeli D, Lehlbach K, LiWeber M, et al. p53 activates the CD95 (APO-1/Fas) gene in response to DNA damage by anticancer drugs. J Exp Med. 1998;188:2033-45.

52. Friesen C, Fulda S, Debatin KM. Deficient activation of the CD95 (APO-1/Fas) system in drug-resistant cells. Leukemia. 1997;11: $1833-41$.
53. Debatin KM, Stahnke K, Fulda S. Apoptosis in hematological disorders. Semin Cancer Biol. 2003;13:149-58.

54. Troeger A, Schmitz I, Siepermann M, Glouchkova L, Gerdemann $\mathrm{U}$, Janka-Schaub GE, et al. Upregulation of c-FLIP $\mathrm{S}_{+\mathrm{R}}$ upon CD40 stimulation is associated with inhibition of CD95-induced apoptosis in primary precursor B-ALL. Blood. 2007;110:384-7.

55. Culjkovic-Kraljacic B, Fernando TM, Marullo R, Calvo-Vidal N, Verma A, Yang S, et al. Combinatorial targeting of nuclear export and translation of RNA inhibits aggressive B-cell lymphomas. Blood. 2016;127:858-68.

56. Johnson NA, Savage KJ, Ludkovski O, Ben-Neriah S, Woods R, Steidl C, et al. Lymphomas with concurrent BCL2 and MYC translocations: the critical factors associated with survival. Blood. 2009; 114:2273-9.

57. Hu S, Xu-Monette ZY, Tzankov A, Green T, Wu L, Balasubramanyam A, et al. MYC/BCL2 protein coexpression contributes to the inferior survival of activated B-cell subtype of diffuse large B-cell lymphoma and demonstrates high-risk gene expression signatures: a report from The International DLBCL RituximabCHOP Consortium Program. Blood. 2013;121:4021-31.

58. Lemke J, von Karstedt S, Zinngrebe J, Walczak H. Getting TRAIL back on track for cancer therapy. Cell Death Differ. 2014;21:1350-64.

59. Maddipatla S, Hernandez-Ilizaliturri FJ, Knight J, Czuczman MS. Augmented antitumor activity against B-cell lymphoma by a combination of monoclonal antibodies targeting TRAIL-R1 and CD20. Clin Cancer Res. 2007;13(15 Pt 1):4556-64.

60. Cohen Y, Chetrit A, Cohen Y, Sirota P, Modan B. Cancer morbidity in psychiatric patients: influence of lithium carbonate treatment. Med Oncol. 1998;15:32-36.

\section{Affiliations}

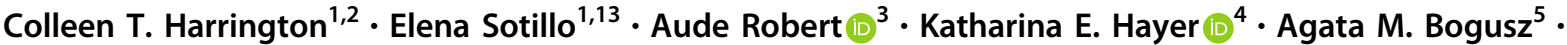

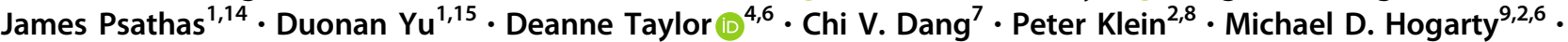 Birgit Geoerger ${ }^{10,11} \cdot$ Wafik S. El-Deiry ${ }^{12} \cdot$ Joëlle Wiels $\mathbb{D}^{3} \cdot$ Andrei Thomas-Tikhonenko $\mathbb{D}^{1,2,5,9}$}

1 Division of Cancer Pathobiology, Children's Hospital of Philadelphia, Philadelphia, PA 19104, USA

2 Cell \& Molecular Biology Graduate Group, Perelman School of Medicine at the University of Pennsylvania, Philadelphia, PA 19104, USA

3 CNRS UMR 8126, Univ Paris-Sud - Université Paris-Saclay, Institut Gustave Roussy, 94805 Villejuif, France

4 Department of Biomedical and Health Informatics, Children's Hospital of Philadelphia, Philadelphia, PA 19104, USA

5 Department of Pathology and Laboratory Medicine, Perelman School of Medicine at the University of Pennsylvania, Philadelphia, PA 19104, USA

6 Department of Pediatrics, Perelman School of Medicine at the University of Pennsylvania, Philadelphia, PA 19104, USA

7 Molecular and Cellular Oncogenesis Program, The Wistar Institute, Philadelphia, PA 19104, USA

8 Department of Medicine, Perelman School of Medicine at the University of Pennsylvania, Philadelphia, PA 19104, USA
9 Division of Oncology, Children's Hospital of Philadelphia, Philadelphia, PA 19104, USA

10 CNRS UMR 8203, Univ Paris-Sud - Université Paris-Saclay, Institut Gustave Roussy, 94805 Villejuif, France

11 Department of Pediatric and Adolescent Oncology, Univ ParisSud - Université Paris-Saclay, Institut Gustave Roussy, 94805 Villejuif, France

12 Department of Pathology and Laboratory Medicine, Brown University Medical School, Providence, RI 02912, USA

13 Present address: Stanford Cancer Institute, 265 Campus Dr., Stanford, CA 94305, USA

14 Present address: The Janssen Pharmaceutical Companies of Johnson \& Johnson, 200 Great Valley Parkway, Malvern, PA 19355, USA

15 Present address: Noncoding RNA Center, Yangzhou University, 225001 Yangzhou, China 